\title{
Simple Formation of Nanostructured Molybdenum Disulfide Thin Films by Electrodeposition
}

\author{
S. K. Ghosh, ${ }^{1}$ C. Srivastava, ${ }^{1}$ S. Nath, ${ }^{2}$ and J. P. Celis ${ }^{3}$ \\ ${ }^{1}$ Materials Processing Division, Bhabha Atomic Research Centre, Trombay, Mumbai 400 085, India \\ ${ }^{2}$ Radiation and Photochemistry Division, Bhabha Atomic Research Centre, Trombay, Mumbai 400 085, India \\ ${ }^{3}$ Department of Metallurgy and Materials, Katholic University of Leuven, 3001 Leuven, Belgium
}

Correspondence should be addressed to S. K. Ghosh; sghosh@barc.gov.in

Received 30 April 2013; Accepted 18 July 2013

Academic Editor: Emmanuel Maisonhaute

Copyright (C) 2013 S. K. Ghosh et al. This is an open access article distributed under the Creative Commons Attribution License, which permits unrestricted use, distribution, and reproduction in any medium, provided the original work is properly cited.

\begin{abstract}
Nanostructured molybdenum disulfide thin films were deposited on various substrates by direct current (DC) electrolysis form aqueous electrolyte containing molybdate and sulfide ions. Post deposition annealing at higher temperatures in the range 450$700^{\circ} \mathrm{C}$ transformed the as-deposited amorphous films to nanocrystalline structure. High temperature X-ray diffraction studies clearly recorded the crystal structure transformations associated with grain growth with increase in annealing temperature. Surface morphology investigations revealed featureless structure in case of as-deposited surface; upon annealing it converts into a surface with protruding nanotubes, nanorods, or dumbbell shape nanofeatures. UV-visible and FTIR spectra confirmed about the presence of Mo-S bonding in the deposited films. Transmission electron microscopic examination showed that the annealed $\mathrm{MoS}_{2}$ films consist of nanoballs, nanoribbons, and multiple wall nanotubes.
\end{abstract}

\section{Introduction}

Molybdenum disulfide, $\mathrm{MoS}_{2}$, that naturally occurs as molybdenite has layered hexagonal packed structure consisting of -S-Mo-S- sheets stacked one after another by van der Waals interactions. Because of its layered structure, it has got very good lubrication properties due to shearing of layers under the application of normal load. It is perhaps most well-known heterogeneous catalyst in industry for hydrodesulfurization (HDS) of petroleum [1]. Apart from these, due to suitable electron band-gap $(\sim 1.7 \mathrm{ev})$, there is an upsurge interest on $\mathrm{MoS}_{2}$ solar cell [2] and solar hydrogen production materials [3-5]. Recently DFT calculations [6] showed that in its nanoparticulate form, $\mathrm{MoS}_{2}$ has demonstrated as promising and inexpensive alternative to platinum for electrochemical and photochemical production of hydrogen from water [7, 8]. It emphasized that presence of edges of S-Mo-S sheet is the active sites; in particular the [1010] Mo-edges have the least energy requirement for bonding hydrogen [7-10]. However, precise molecular structure and modes of action of these sites remain unresolved. Therefore, the synthesis of $\mathrm{MoS}_{2}$ nanoparticulate or nanostructured form having maximum edges of S-Mo-S sheets is of recent investigations concern. Several synthetic approaches like wet inorganic solvent route, template-based, and chemical vapor deposition techniques have been followed [9-15] to prepare such nanoparticulate or nanostructured $\mathrm{MoS}_{2}$ in order to maximize the sulfide edge effect on hydrogen generation. Synthesis of such $\mathrm{MoS}_{2}$ nanoparticles or nanostructured forms via stable amorphous precursor followed by crystallization could be a viable alternative. Previous attempts [16-18] for synthesis of $\mathrm{MoS}_{3}$ or $\mathrm{MoS}_{x}$ films for photovoltaic applications via electrochemical deposition would result in the formation of amorphous films. A heat treatment after film deposition had shown to crystallize the film into $2 \mathrm{~h}-\mathrm{MoS}_{2}$ structure [17]. Therefore, it is important to explore synthesis of $\mathrm{MoS}_{2}$ films consisting of nanorods, nanotubes, or other nanofeatures via amorphous precursor by electrodeposition.

In the present study, a simple DC electrolysis was employed to produce amorphous $\mathrm{MoS}_{2}$ film on cathode containing transition metal surfaces. Maintaining very high concentration of sodium sulfide in the electrolyte and using transition metal substrates as cathode material were two major changes adopted in this study in comparison to [16]. 
In case of former, prevailing idea was to maintain strong $\mathrm{H}_{2} \mathrm{~S}$ evolution, while electrolysis thereby maximized $\mathrm{MoS}_{2}$ formation suppressing $\mathrm{MoO}_{x}$ growth. Reason behind using transition metal surface as cathode materials was that, being catalytic in nature, these substrates might accelerate the nanotube/nanorod or nanoball formation during annealing. Therefore, in order to form nanostructured $\mathrm{MoS}_{2}$ film consisting of several nanofeatures, post deposition films were given suitable annealing treatment. Detailed structural characterization of as-deposited as well as annealed films was carried out utilizing FTIR, UV-visible, X-ray diffraction (XRD), field emission scanning electron microscope (FESEM), and transmission electron microscope (TEM).

\section{Experimental}

DC electrolysis was carried out to deposit $\mathrm{MoS}_{2}$ films from an electrolyte containing sodium molybdate $(0.5 \mathrm{M})$ and sodium sulfide $(30 \mathrm{~g} / \mathrm{L})$. The $\mathrm{pH}$ of the electrolyte was adjusted to 7 by adding dilute sulphuric acid. A two-electrode system having $\mathrm{Pt}$ as anode and substrate as cathode was employed for $\mathrm{MoS}_{2}$ film growth. Typical substrates used were copper, electroless $\mathrm{Ni}$, and CoW alloy in order to study the catalytic effect of substrates on fullerene/nanotube growth. All these substrates were cleaned first in alkaline solution followed by acid dip in a $10 \%$ sulphuric acid solution. Polarization experiments were carried out in EG\&G PAR 273 potentiostat/galvanostat. Here, a Pt sheet was used as counter electrode, and $\mathrm{Ag} / \mathrm{AgCl}$ electrode was used as reference electrode. After deposition, films were annealed in vacuum or in argon atmosphere at $450-600^{\circ} \mathrm{C}$ for $5 \mathrm{hrs}$ for crystallization. The heating rate was maintained at $5^{\circ} \mathrm{C} \mathrm{min}{ }^{-1}$. A 3D-optical profilometer was used for film thickness determination from step-height measurement. To record Fourier Transform Infrared (FTIR) spectra, Bomem Hartmann and Braun MB Series Infrared spectrometer was used. Annealed $\mathrm{MoS}_{2}\left(450^{\circ} \mathrm{C}\right.$ for $\left.5 \mathrm{hrs}\right)$ powder was crushed with $\mathrm{KBr}$ particles $(1: 5)$ and pressed into thin pellets for FTIR measurements in transmission mode. UV-Vis absorption spectra of annealed $\mathrm{MoS}_{2}$ powder in water were recorded with JASCO spectrophotometer (model number V-650) using a quartz cell of $1 \mathrm{~cm}$ optical path length.

Surface morphology was examined under Philips XL-30 FE-SEM equipped with EDS facility. Both room temperature and high temperature XRD were carried out in Seifert 3003-TT X-ray diffractometer using $\mathrm{CuK} \alpha 1$ radiation. For microstructural investigation by TEM, the $\mathrm{MoS}_{2}$ films were scrapped off from the substrate and dispersed in absolute ethanol (AR grade) by sonication. Then, a drop of this dispersion was placed on carbon coated copper grid and dried in nitrogen before analysis in the TEM (JEOL-2010) operated at $200 \mathrm{kV}$.

\section{Results and Discussions}

3.1. Deposition of $\mathrm{MoS}_{2}$ Films. The electrolytic formation of $\mathrm{MoS}_{2}$ followed by deposition on the cathode surface is basically a two-step process. First step involves an in situ chemical conversion of molybdate to thiomolybdate ions which is followed by electrochemical reduction to $\mathrm{MoS}_{2}$ at the cathode surface. Addition of initial precursor $\mathrm{MoO}_{4}{ }^{2-}$ and excess of $\mathrm{S}^{2-}$ ions gave rise to $\mathrm{pH}>12$ of the electrolyte. On adding slowly a $10 \% \mathrm{H}_{2} \mathrm{SO}_{4}$ solution, the electrolyte color changed to yellow with release of $\mathrm{H}_{2} \mathrm{~S}$ gas. Once $\mathrm{pH}$ of the electrolyte brought down below 9.0, the electrolyte color became brownish to deep brown. On further addition of acid, the $\mathrm{H}_{2} \mathrm{~S}$ evolution increased inducing a simultaneous conversion of $\mathrm{MoO}_{4}{ }^{2-}$ to $\mathrm{MoS}_{4}{ }^{2-}$ by the following reaction:

$$
\mathrm{MoO}_{4}{ }^{2-}+6 \mathrm{~S}^{2-}+12 \mathrm{H}^{+} \longleftrightarrow \mathrm{MoS}_{4}{ }^{2-}+4 \mathrm{H}_{2} \mathrm{O}+2 \mathrm{H}_{2} \mathrm{~S} \uparrow
$$

This chemically formed thiomolybdate $\left(\mathrm{MoS}_{4}{ }^{2-}\right)$ ion basically acted as precursor for cathodic discharge [16]. This cathodic reduction reaction at the electrode surface results in the in situ formation of $\mathrm{MoS}_{x}$ thin films by the following reaction:

$$
\mathrm{MoS}_{4}{ }^{2-}+6 \mathrm{H}^{+}+2 \mathrm{e}^{-} \longleftrightarrow \mathrm{MoS}_{2}+2 \mathrm{H}_{2} \mathrm{~S} \uparrow+\mathrm{H}_{2} \uparrow
$$

We note here that the unreacted molybdate $\left(\mathrm{MoO}_{4}{ }^{2-}\right)$ ions are also in competition with $\mathrm{MoS}_{4}{ }^{2-}$ ion for discharge at the cathode surface. Therefore, it is required to investigate the polarization curves of sodium molybdate and mixed electrolyte (molybdate-sulfide) individually for selection of voltage/current in order to maximize $\mathrm{MoS}_{2}$ formation at the cathode surface.

Figure 1 shows the polarization curves of sodium molybdate, sodium sulfide, and molybdate-sulfide mixed electrolyte at pH 7 separately to understand the electrochemical behaviour. We note that the $I-V$ curve of sodium sulfide does not have any specific feature except hydrogen evolution. Unlike sodium sulfide, both molybdate and mixed electrolyte $\left(\mathrm{Na}_{2} \mathrm{MoO}_{4}+\mathrm{Na}_{2} \mathrm{~S}\right)$ possess plateau region which is an indication of mixed mode (activation as well-diffusion control) control of discharge of respective species at the cathode surface. Both molybdate and thiomolybdate ions start discharge at $\sim-0.283 \mathrm{~V}$ versus $\mathrm{Ag} / \mathrm{AgCl}$. However, it is seen that at any point of potential, the current density due to discharge of thiomolybdate ion is higher than molybdate ion. On further increase of the potential towards cathodic direction, the current density due to the discharge of thiomolybdate ions exceeds the current density produced by molybdate ions reduction. Therefore, a current density range $\geq 10 \mathrm{~mA} \cdot \mathrm{cm}^{-2}$ was chosen to minimize $\mathrm{MoO}_{2}$ content in $\mathrm{MoS}_{2}$ film. Of course, the presence of excess $\mathrm{S}^{2-}$ ion in the electrolyte would push the reaction in the forward direction of equation 1 resulting into higher concentration of $\mathrm{MoS}_{4}{ }^{2-}$ ion. Here, thin film deposition were carried out at $\mathrm{pH} 7.0$ so that the electrolyte was kept stable without any precipitation of $\mathrm{MoS}_{3}$ as would occur at further lower $\mathrm{pH}$. The deposited films were black in color. EDS analysis confirmed composition of the film with $S:$ Mo $~ 1.7$. Figure 2(a) shows 3D surface topography of step edge of $\mathrm{MoS}_{2}$ films on NiP substrate deposited for a duration of 3 minutes and Figure 2(b) is corresponding $2 \mathrm{D}$ pattern. Typical thickness obtained after 3 - and 4-minute deposition time was $\sim 400 \mathrm{~nm}$ and $\sim 500 \mathrm{~nm}$, respectively, as given in Table 1, and 30-50\% film shrinkage 


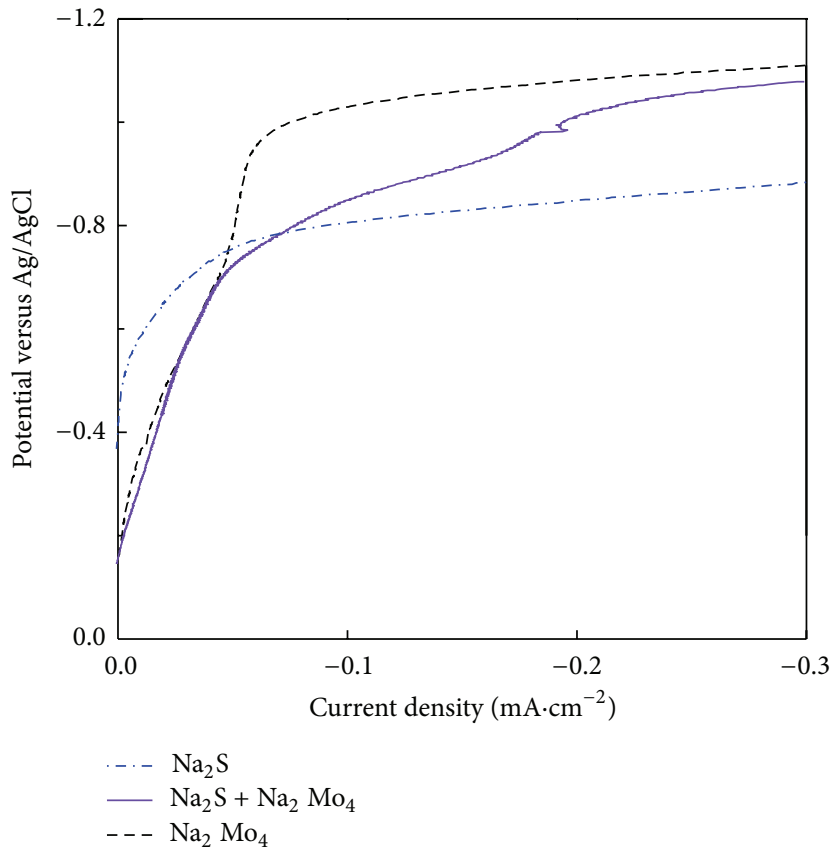

FIgure 1: Polarization curves of $\mathrm{Na}_{2} \mathrm{MoO}_{4}, \mathrm{Na}_{2} \mathrm{~S}$, and $\mathrm{Na}_{2} \mathrm{MoO}_{4}+\mathrm{Na}_{2} \mathrm{~S}$ mixed electrolytes. Inset shows enlarged view of onset of discharge potentials for individual electrolytes. Scan rate was $5 \mathrm{mV} \cdot \mathrm{s}^{-1}$.

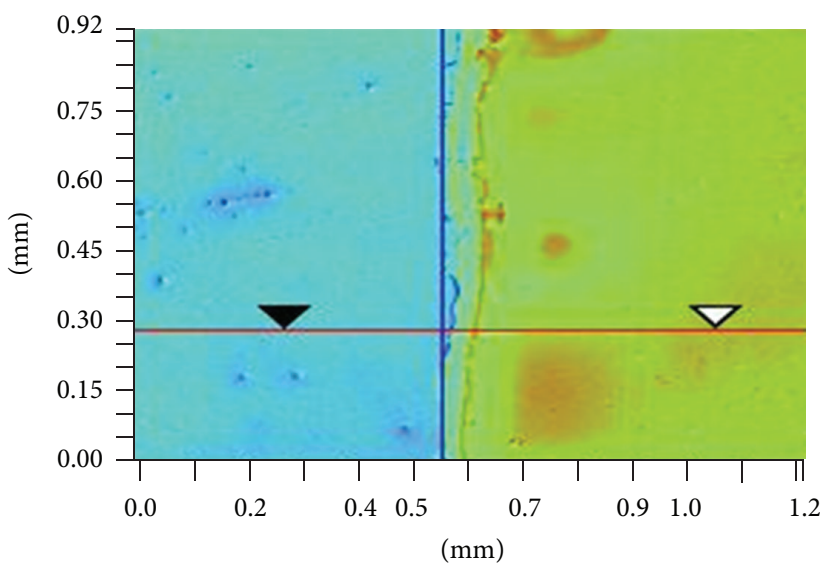

(a)

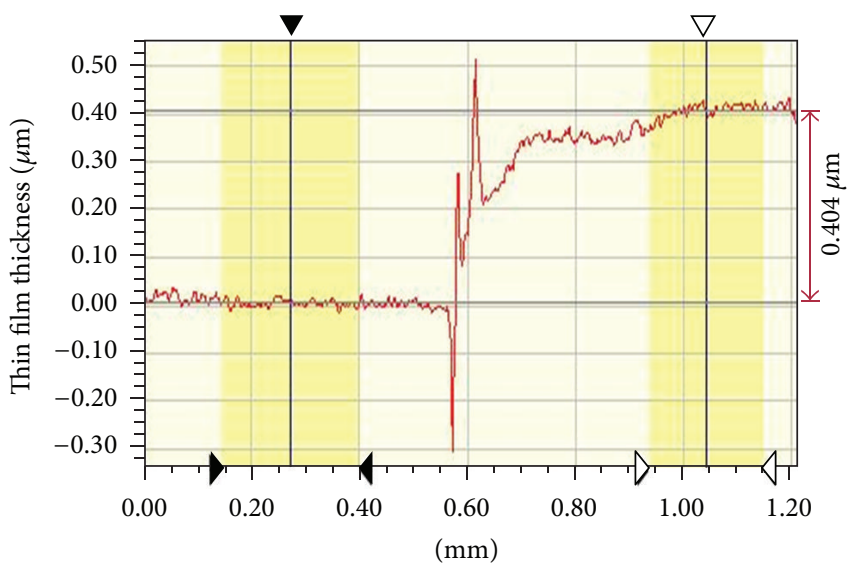

(b)

Figure 2: (a) 3D surface topography of step edge of $\mathrm{MoS}_{2}$ films on NiP substrate deposited for a duration of 3 minutes, (b) 2D pattern of line scan of Figure 2(a).

was noticed upon annealing. $\mathrm{MoS}_{2}$ films were found to peel off from the substrate beyond thickness of $500 \mathrm{~nm}$ due to poor adhesion. Film thickness reduction upon annealing could be due to loss of adsorbed water molecules followed by compaction owing to sintering and crystallization process.

The UV-Vis absorption spectrum was measured on scraped annealed $\left(500^{\circ} \mathrm{C}\right.$ for $\left.5 \mathrm{hrs}\right) \mathrm{MoS}_{2}$ powder sample (Figure 3(a)) and shows the features that can be assigned to the $\mathrm{A}, \mathrm{B}$, and $\mathrm{C}$ excitons, characteristics of the $2 \mathrm{H}$-polytype [19]. The latter two excitons B $(625 \mathrm{~nm})$ and C $(682 \mathrm{~nm})$ with a splitting of approximately $60 \mathrm{~nm}$ corresponds to interlayer interaction and spin-orbit splitting [20]. This is in good agreement with the literature [21]. Normally, a red
TABLE 1: Dependence of $\mathrm{MoS}_{2}$ thin film thickness on deposition time and heat treatment.

\begin{tabular}{lcc}
\hline $\begin{array}{l}\text { Deposition time } \\
(\text { min. })\end{array}$ & $\begin{array}{c}\text { As-deposited film } \\
\text { thickness }(\mathrm{nm})\end{array}$ & $\begin{array}{c}\text { Annealed film } \\
\text { thickness }(\mathrm{nm})\end{array}$ \\
\hline 3 & 404 & 223 \\
4 & 511 & 341 \\
\hline
\end{tabular}

shift in these two peak positions occurs in case of coaxial $\mathrm{MoS}_{2}$ nanotubes; however, here the annealed sample seems a mixture of exfoliated $\mathrm{MoS}_{2}$ with the appearance of shoulder A at $400 \mathrm{~nm}$ [20] with other nano-features as can be seen below 


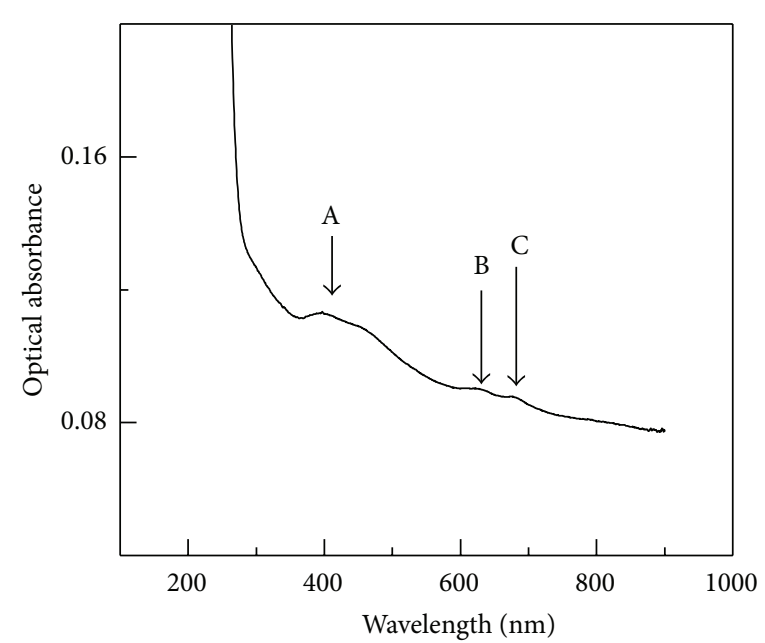

(a)

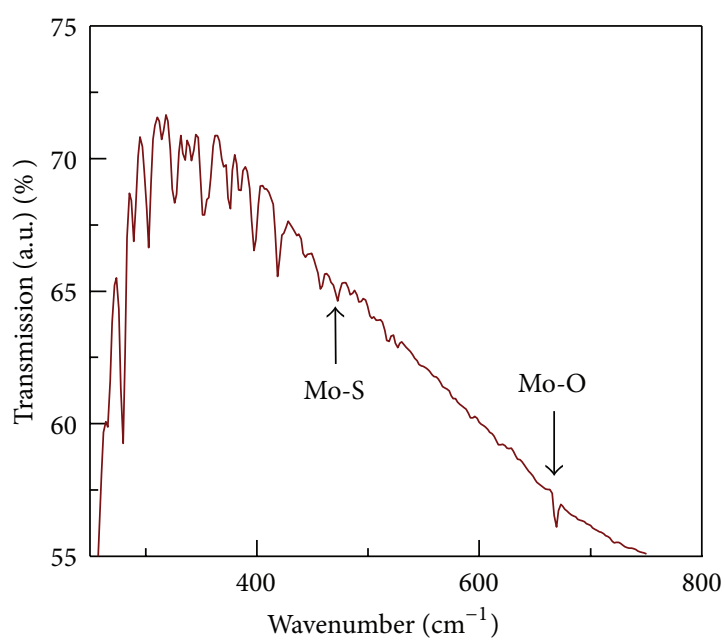

(b)

FIgure 3: (a) UV-visible spectrum of annealed $\mathrm{MoS}_{2}$ film powder. (b) FTIR spectrum of annealed $\mathrm{MoS}_{2}$ films. Annealing condition: $450^{\circ} \mathrm{C}$ for $5 \mathrm{hrs}$ in vacuum.

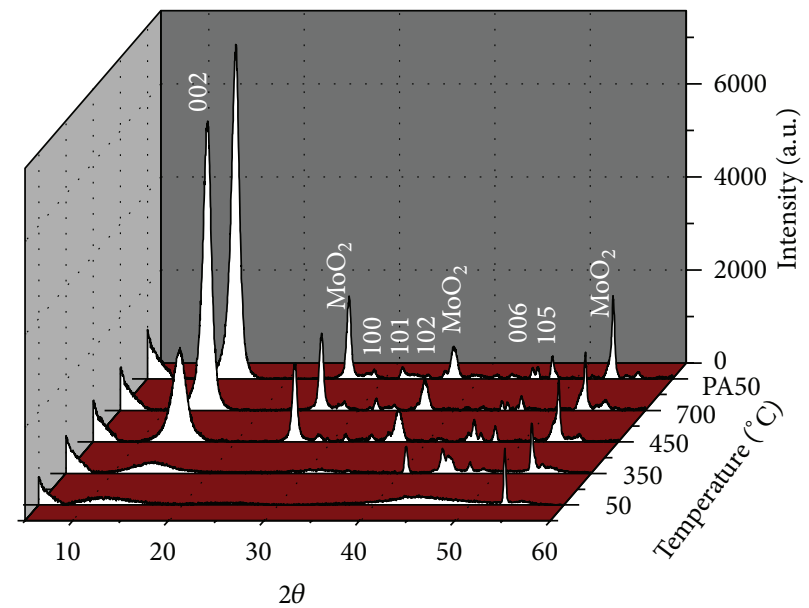

FIGURE 4: XRD pattern of $\mathrm{MoS}_{2}$ thin film at different temperatures recorded during stepwise annealing. Here "PA50" represents XRD pattern of annealed $\left(700^{\circ} \mathrm{C}\right) \mathrm{MoS}_{2}$ film at $50^{\circ} \mathrm{C}$.

from SEM and TEM results. The presence of Mo-S bond in the annealed sample was further ascertained from FTIR spectra as shown in Figure 3(b). The weak peak at $472 \mathrm{~cm}^{-1}$ corresponds to Mo-S vibration of $\mathrm{MoS}_{2}$ [22], and the other band at $690 \mathrm{~cm}^{-1}$ match with $\gamma(\mathrm{Mo}-\mathrm{O})$ vibrations [23]. This indicates coexistence of sulfides and oxides in the film.

3.2. Crystal Structure and Phase Analysis. Figure 4 shows XRD pattern of as-deposited as well as annealed $\mathrm{MoS}_{2}$ films deposited on NiP substrate. It confirms amorphous nature of as-deposited film. In order to study the crystallization process, post deposition films were annealed in argon atmosphere with a heating rate of $5^{\circ} \mathrm{C} \mathrm{min}^{-1}$, and crystal structure was monitored via in-situ XRD. At each temperature, films were hold for 20 minutes for equilibration in crystal structure. The obtained XRD peaks were indexed from ICPDF database and previous literature $[13,24-26]$. It is clear from Figure 4 that with increase in temperature, the intensity of hexagonal (002) reflection increases and peak width becomes sharper giving rise to an indication of growth of crystallite sizes. Besides this, other low intensity peaks also start appearing at temperatures $\geq 450^{\circ} \mathrm{C}$. The sharp appearance of (002) peak is a clear indication of structural transformation from amorphous to crystalline phases and highly texture along $\langle 002\rangle$ direction. Appearance of low intensity $\mathrm{MoO}_{2}$ peak suggests presence of minute quantity $\mathrm{MoO}_{2}$ phases. It supports the FTIR spectra about the presence of oxides in the film along with $\mathrm{MoS}_{2}$. Detailed peak analysis (position and broadening) of (002) reflections of post annealed $50^{\circ} \mathrm{C}$ sample (represented as PA50), results into $d$ value of $0.621 \mathrm{~nm}$ and grain size of $10 \mathrm{~nm}$. This lattice parameter indicates approximately 97\% lattice expansion compared to $2 \mathrm{~h}$ hexagonal structure and matches well with reported inorganic fullerene lattice parameter $[13,26]$.

3.3. Surface Morphology and Microstructural Investigations. FESEM examination of as-deposited $\mathrm{MoS}_{2}$ films on NiP substrate results in featureless surface as shown in Figure 5(a). 


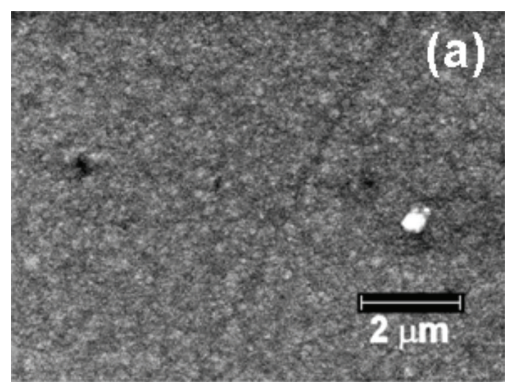

(a)

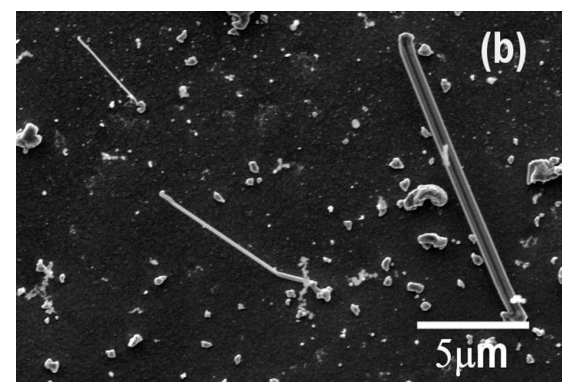

(b)

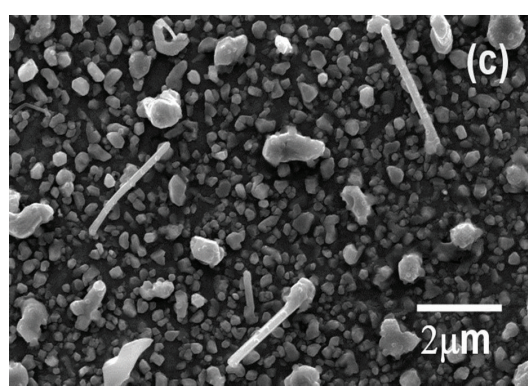

(c)

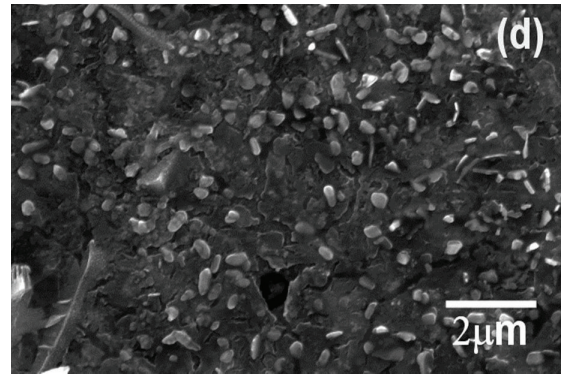

(d)

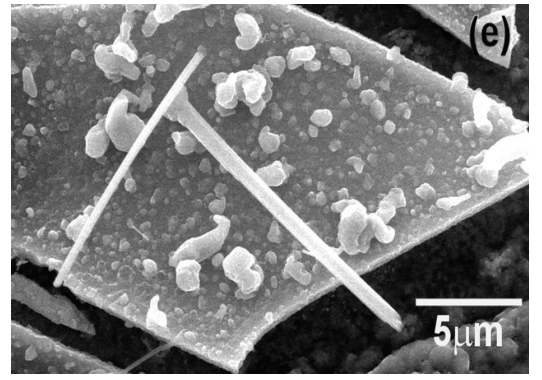

(e)

FIgURE 5: (a) FESEM image of as-deposited $\mathrm{MoS}_{2}$ films on NiP surface; (b) surface topography of $\mathrm{MoS}_{2}$ annealed $\left(450^{\circ} \mathrm{C}\right.$ for $5 \mathrm{hrs}$ ) films deposited on NiP substrate showing nanotubes growth; (c) same surface as on (b) showing several nanotube or nanorods growth; (d) Growth

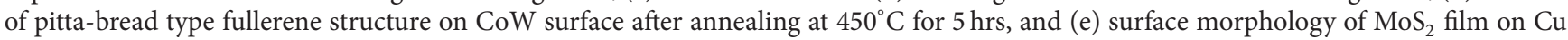
substrate showing film delamination and nanotube/nanorod formation.

Upon annealing at $450^{\circ} \mathrm{C}$ for $5 \mathrm{hrs}$, growth of several nanotubes/nanorods, half-cut nanotubes of several micrometer in length with diameter $\sim 10-100 \mathrm{~nm}$, and nanoballs is visible on the surface (Figures 5(b) and 5(c)). We note that the growth of such nanorods/nanotubes is very similar to wishker growth. A close look into the half-cut nanotube (Figure 5(b)) reveals that such nantube surrounds multiple walls of $\mathrm{MoS}_{2}$ sheets and defect mediated growth. On CoW substrate, $\mathrm{MoS}_{2}$ fullerenes have grown with different shapes similar to pittabread type or hollow dumb-bell shape features (Figure 5(d)) [27]. Figure 5(e) shows surface morphology of annealed $\mathrm{MoS}_{2}$ film on $\left(450^{\circ} \mathrm{C}\right.$ for $\left.5 \mathrm{hrs}\right)$ grown on Cu substrate. Here, the formation of cracks and film delamination associated with growth of nano- and mesotubes/rods and several small protrusions on film layer could be seen. Occurrence of such cracks and film delamination is the result of stress release or due to large difference in thermal expansion coefficient of metal and $\mathrm{MoS}_{2}$ film.

Figure 6(a) shows transmission electron microscope image of annealed $\left(600^{\circ} \mathrm{C}\right.$ for $\left.2 \mathrm{hrs}\right) \mathrm{MoS}_{2}$ film. TEM investigation of such annealed $\mathrm{MoS}_{2}$ films revealed that it consisted of several nanofeatures like nanoballs with sizes from 5 to $10 \mathrm{~nm}$ and nanosheets or nanoribbons with $\sim 10 \mathrm{~nm}$ width and several nanometer in lengths. It seems that formation of nanosheets from the amorphous precursor is the first step. When these nanosheets are sufficient in length, they undergo winding up assuming a hexagonal shape (as shown in Figure 6(a)) to form a nanotube, nanorod, other nanofeatures. It is evident that these sheets are multiple in layers and clear faceting towards the formation of a hexagon. Selected area diffraction (SAED) with spotty ring pattern of annealed $\mathrm{MoS}_{2}$ film also corroborates the XRD results of well-crystalline nature of the film (inset of Figure 6(a)). Microstructural investigation of annealed $\mathrm{MoS}_{2}$ film for longer duration $\left(450^{\circ} \mathrm{C}\right.$ for $\left.5 \mathrm{hrs}\right)$ reveals the formation of multiwall nanotube as shown in Figure 6(b). It supports the previous section SEM investigation results. Therefore, the microstructure of annealed $\mathrm{MoS}_{2}$ consists of several nanofeatures starting from nanosheet, nanoribbon, nanoballs, nanoballs, and nanorods/nanoubes depending upon temperature, annealing duration, and substrate.

\section{Conclusions}

$\mathrm{MoS}_{2}$ films containing several nano-features like nanoballs, nanorods/nanotubes, and nanoribbons were successfully synthesized by simple DC electrodeposition followed by post annealing treatment. Being a very fast deposition process, a compact $\mathrm{MoS}_{2}$ film of thickness $\sim 400-500 \mathrm{~nm}$ could be obtained within 3-4 minutes duration. X-ray diffraction confirmed the initiation of crystallization process of asdeposited amorphous precursor films at $450^{\circ} \mathrm{C}$ and higher temperature favors such process. UV-visible and FTIR spectra confirmed the presence of Mo-S as well as Mo-O bonds in the annealed films. FESEM investigations of annealed $\mathrm{MoS}_{2}$ film (annealed at $450^{\circ} \mathrm{C}$ for $5 \mathrm{hrs}$ in vacuum or in argon atmosphere) surface revealed the formation of $\mathrm{MoS}_{2}$ nanoube/nanorod and nanoballs on $\mathrm{Ni}$ and $\mathrm{Cu}$ substrates and pitta-bread type nanofeatures on CoW substrate. The size of the nanotubes/nanorods varied from $200 \mathrm{~nm}$ to 1 micron on $\mathrm{Ni}$ and $\mathrm{Cu}$ substrates. TEM examinations confirmed the initiation of hexagonal nanotube formation via bending of 


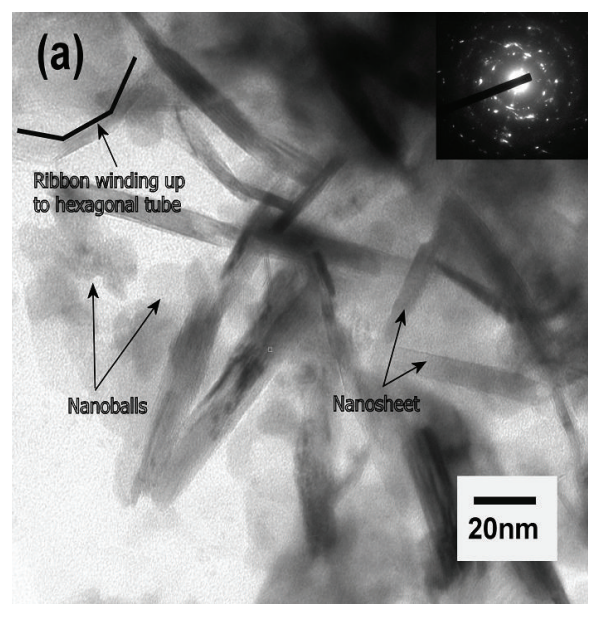

(a)

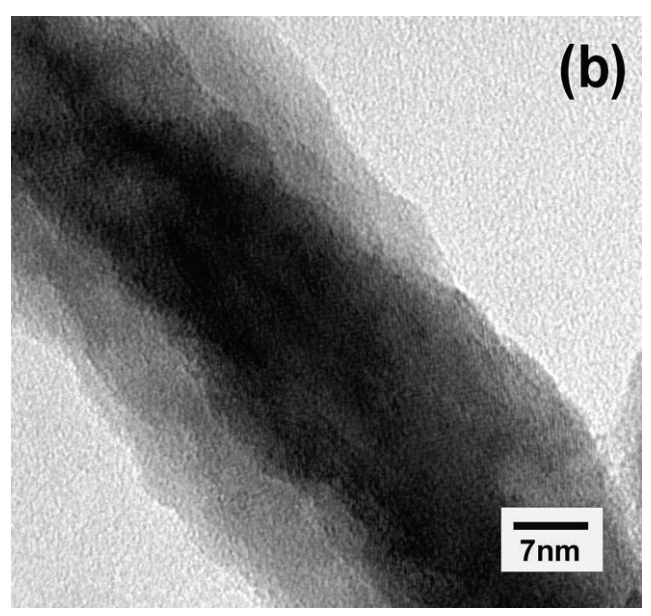

(b)

FIGURE 6: (a) TEM micrograph showing presence of nanoribbons, nanoballs in postannealed samples $\left(600^{\circ} \mathrm{C}\right.$ for $\left.2 \mathrm{hrs}\right)$ and (b) TEM image of multiwall $\mathrm{MoS}_{2}$ nanotube $\left(450^{\circ} \mathrm{C}\right.$ for $\left.5 \mathrm{hrs}\right)$.

nano-ribbons, presence of ribbons, and balls of nanometer in size. It also confirmed the presence of multiple-wall nanotubes. This study unearths that electrodeposition is a simple growth technique for synthesizing nanostructured $\mathrm{MoS}_{2}$ films which may help in future in making catalyst and/or electrode materials for photoelectrochemical or electrochemical hydrogen production.

\section{Acknowledgments}

S. K. Ghosh thanks the European Commission for a Marie Curie Incoming International Fellowship (FP7-PEOPLE2007-4-2-IIF-220002-NANOCOAT) granted to him under FP-7 framework program. The authors wish to thank Dr. V. Sudarshan, Chemistry Division, Bhabha Atomic Research Centre, for his help in carrying out FTIR spectra.

\section{References}

[1] H. Topsøe, B. S. Clausen, and F. E. Massoth, Hydrotreating Catalysis Science and Technology, vol. 11, edited by J. R. Anderson and M. Boudart, Springer, New York, NY, USA, 1996.

[2] J. V. Lauritsen, J. Kibsgaard, S. Helveg et al., "Size-dependent structure of $\mathrm{MoS}_{2}$ nanocrystals," Nature Nanotechnology, vol. 2, no. 1, pp. 53-58, 2007.

[3] T. F. Jaramillo, K. P. Jørgensen, J. Bonde, J. H. Nielsen, S. Horch, and I. Chorkendorff, "Identification of active edge sites for electrochemical $\mathrm{H}_{2}$ evolution from $\mathrm{MoS}_{2}$ nanocatalysts," Science, vol. 317, no. 5834, pp. 100-102, 2007.

[4] T. R. Thurston and J. P. Wilcoxon, "Photooxidation of organic chemicals catalyzed by nanoscale $\mathrm{MoS}_{2}$," Journal of Physical Chemistry B, vol. 103, no. 1, pp. 11-17, 1999.

[5] X. Zong, H. Yan, G. Wu et al., "Enhancement of photocatalytic $\mathrm{H}_{2}$ evolution on CdS by loading $\mathrm{MoS}_{2}$ as cocatalyst under visible light irradiation," Journal of the American Chemical Society, vol. 130, pp. 7176-7177, 2008.

[6] B. Hinnemann, P. G. Moses, J. Bonde et al., "Biomimetic hydrogen evolution: $\mathrm{MoS}_{2}$ nanoparticles as catalyst for hydrogen evolution," Journal of the American Chemical Society, vol. 127, pp. 5308-5309, 2005.

[7] B. Hinnemann, J. K. Nørskov, and H. Topsøe, "A Density Functional Study of the chemical differences between Type I and Type II $\mathrm{MoS}_{2}$-based structures in hydrotreating Catalysts," The Journal of Physical Chemistry B, vol. 109, no. 6, pp. 22452253, 2005.

[8] Y. Li, H. Wang, L. Xie, Y. Liang, G. Hong, and H. Dai, "MoS nanoparticles grown on graphene: an advanced catalyst for the hydrogen evolution reaction," Journal of the American Chemical Society, vol. 133, no. 19, pp. 7296-7299, 2011.

[9] H. I. Karunadasa, E. Montalvo, Y. Sun, M. Majda, J. R. Long, and C. J. Chang, "A molecular $\mathrm{MoS}_{2}$ edge site mimic for catalytic hydrogen generation," Science, vol. 335, no. 6069, pp. 698-702, 2012.

[10] A. B. Laursen, S. Kegnaes, S. Dhal, and I. Chorkendroff, "Molybdenum sulfides-efficient and viable materials for electro- and photoelectrocatalytic hydrogen evolution," Energy \& Environmental Science, vol. 5, pp. 5577-5591, 2012.

[11] L. P. Hansen, Q. M. Ramasse, C. Kisielowski et al., "Atomicscale edge structures on industrial-style $\mathrm{MoS}_{2}$ nanocatalysts," Angewandte Chemie International Edition, vol. 50, no. 43, pp. 10153-10156, 2011.

[12] J. V. Lauritsen, M. V. Bollinger, E. Lægsgaard et al., "Atomicscale insight into structure and morphology changes of $\mathrm{MoS}_{2}$ nanoclusters in hydrotreating catalysts," Journal of Catalysis, vol. 221, no. 2, pp. 510-522, 2004.

[13] R. Tenne, Silicon Versus Carbon, NATO Science for Peace and Security Series B: Physics and Biophysics, 2009.

[14] Q. Xiang, J. Yu, and M. Jaroniec, "Synergetic effect of $\mathrm{MoS}_{2}$ and graphene as cocatalysts for enhanced photocatalytic $\mathrm{H}_{2}$ production activity of $\mathrm{TiO}_{2}$ nanoparticles," Journal of the American Chemical Society, vol. 134, no. 15, pp. 6575-6578, 2012.

[15] F. Xiangpeng, L. Saifen, S. Yifeng et al., "Lithium storage performance in ordered mesoporous $\mathrm{MoS}_{2}$ electrode material," Microporous and Mesoporous Materials, vol. 151, pp. 418-423, 2012.

[16] E. A. Ponomarev, M. Neumann-Spallart, G. Hodes, and C. Lévy-Clément, "Electrochemical deposition of $\mathrm{MoS}_{2}$ thin films 
by reduction of tetrathiomolybdate," Thin Solid Films, vol. 280, no. 1-2, pp. 86-89, 1996.

[17] A. Albu-Yaron, C. Lévy-Clément, A. Katty, S. Bastide, and R. Tenne, "Influence of the electrochemical deposition parameters on the microstructure of $\mathrm{MoS}_{2}$ thin films," Thin Solid Films, vol. 361-362, pp. 223-228, 2000.

[18] R. N. Bhattacharya, C. Y. Lee, F. H. Pollak, and D. M. Schleich, "Optical study of amorphous $\mathrm{MoS}_{3}$ : determination of the fundamental energy gap," Journal of Non-Crystalline Solids, vol. 91, no. 2, pp. 235-242, 1987.

[19] R. Coehoorn, C. Haas, J. Dijkstra, and C. J. F. Flipse, "Electronic structure of $\mathrm{MoSe}_{2}, \mathrm{MoS}_{2}$, and WSe $-\mathrm{I}$. Band-structure calculations and photoelectron spectroscopy," Physical Review B, vol. 35, pp. 6195-6202, 1987.

[20] B. Visic, R. Dominko, M. K. Gunde, N. Hauptman, S. D. Skapin, and M. Remskar, "Optical properties of exfoliated $\mathrm{MoS}_{2}$ coaxial nanotubes-analogues of graphene," Nanoscale Research Letters, vol. 6, article 593, 2011.

[21] G. L. Frey, S. Elani, M. Homyonfer, Y. Feldman, and R. Tenne, "Optical-absorption spectra of inorganic fullerenelike $\mathrm{MS}_{2}(\mathrm{M}$ = Mo, W)," Physical Review B, vol. 57, no. 11, pp. 6666-6671, 1998.

[22] S. Liu, X. Zhang, H. Shao, J. Xiu, F. Chen, and Y. Feng, "Preparation of $\mathrm{MoS}_{2}$ nanofibers by electrospinning," Materials Letters, vol. 73, pp. 223-225, 2012.

[23] G. Nagaraju, C. N. Tharamani, G. T. Chandrappa, and J. Livage, "Hydrothermal synthesis of amorphous $\mathrm{MoS}_{2}$ nanofiber bundles via acidification of ammonium heptamolybdate tetrahydrate," Nanoscale Research Letters, vol. 2, no. 9, pp. 461-468, 2007.

[24] M. Chhowalla and G. A. J. Amaratunga, "Thin films of fullerene-like $\mathrm{MoS}_{2}$ nanoparticles with ultra-low friction and wear," Nature, vol. 407, no. 6801, pp. 164-167, 2000.

[25] R. Tenne, L. Margulis, M. Genut, and G. Hodes, "Polyhedral and cylindrical structures of tungsten disulphide," Nature, vol. 360, no. 6403, pp. 444-446, 1992.

[26] A. M. Panich, A. I. Shames, R. Rosentsveig, and R. Tenne, "A magnetic resonance study of $\mathrm{MoS}_{2}$ fullerene-like nanoparticles," Journal of Physics: Condensed Matter, vol. 21, Article ID 395301, 39 pages, 2009.

[27] R. Rosentsveig, A. Margolin, A. Gorodnev et al., "Synthesis of fullerene-like $\mathrm{MoS}_{2}$ nanoparticles and their tribological behavior," Journal of Materials Chemistry, vol. 19, no. 25, pp. 4368-4374, 2009. 

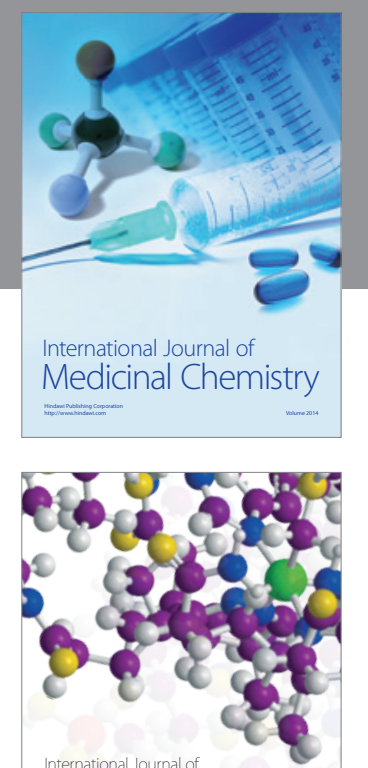

\section{Carbohydrate} Chemistry

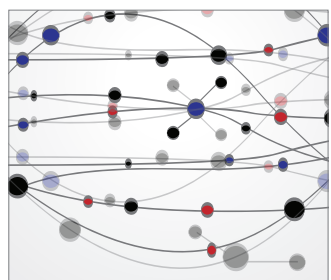

The Scientific World Journal
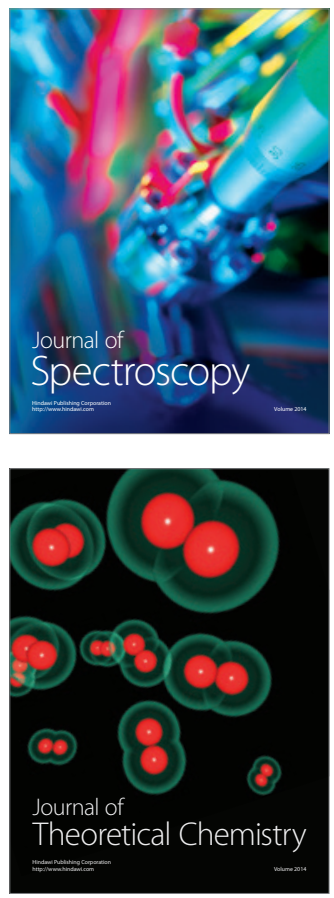
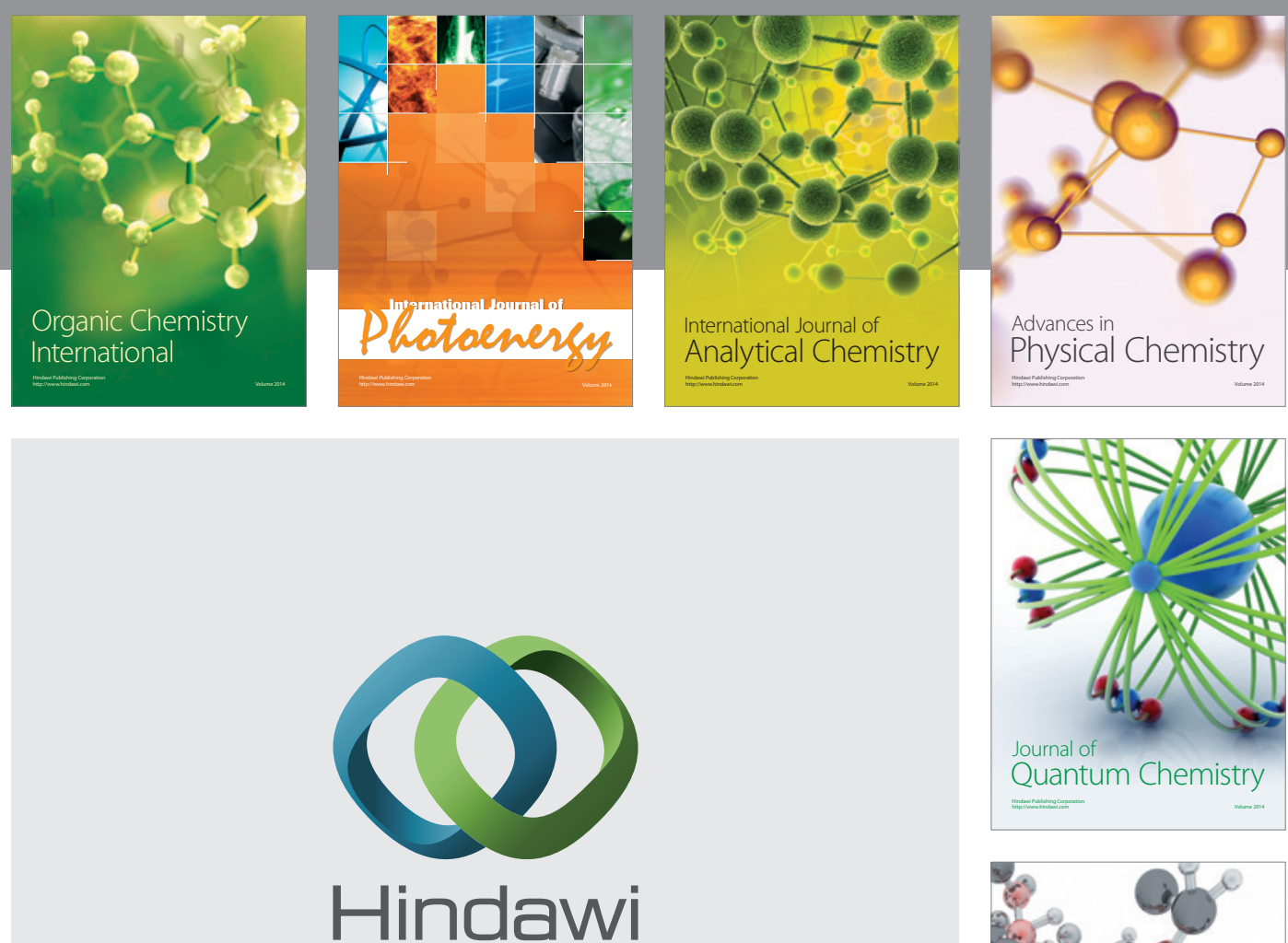

Submit your manuscripts at

http://www.hindawi.com

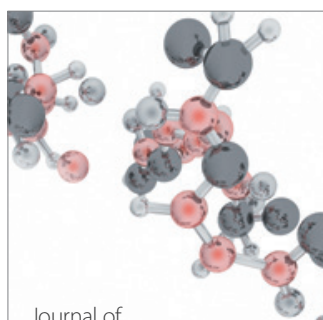

Analytical Methods

in Chemistry

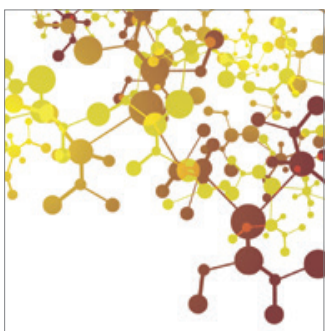

Journal of

Applied Chemistry

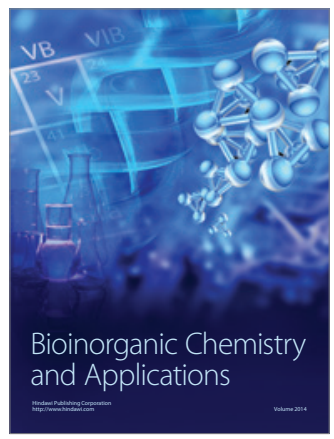

Inorganic Chemistry
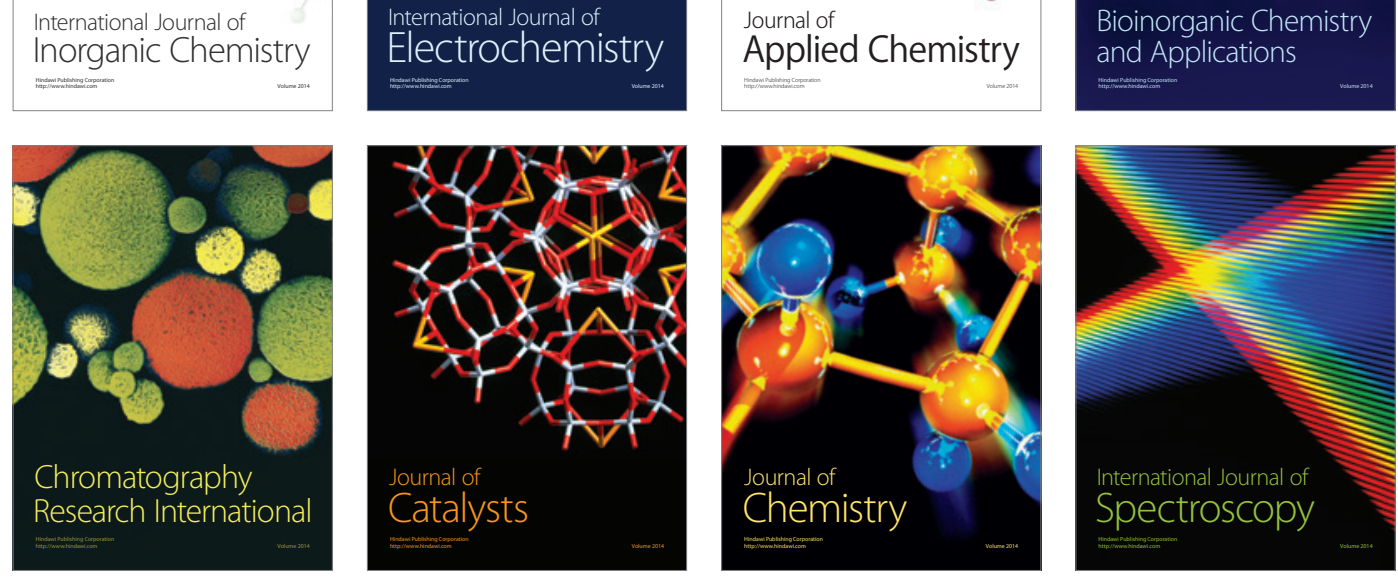